\title{
The ontology of the architectural work and its closeness to the culinary work
}

\author{
Fabio Bacchini* (1)
}

\begin{abstract}
According to a standard view, architectural works are nothing but material buildings. This paper argues that this is just one of many options, each of which may capture more incisively what architects really produce in different circumstances. Three fundamental splits are examined. First, architectural works can be regarded as either objects or events. Second, they can be understood as mere abstract entities, types, or concrete particulars. Third, they can be identified narrowly or broadly. The resulting combinations are explored and tested against concrete situations. The paper argues that, while adopting the type view in conjunction with the narrow view is simpler when we consider stereotypical, vernacular or modular architecture, when we have to do with more experimental and creative approaches it seems more appropriate to identify the architectural work with a broadly identified concrete particular or, at most, with a broadly identified abstract entity that can hardly coincide with the content of the architectural design. The paper highlights that the same goes - mutatis mutandis — for traditional and stereotypical cooking, on the one hand, and haute cuisine, on the other hand. So the paper is also an investigation of the closeness between architecture and cooking, and of the contingent character of some of their differences.
\end{abstract}

Keywords: Ontology, Metaphysics, Architecture, Cooking, Architectural design, Recipe

\section{The building view}

Let us stipulate to call 'architectural works' whatever architects essentially and eventually produce as architects. What are architectural works? What do they consist in? On a very pragmatic, rough view, architectural works are nothing but material buildings. The profession of an architect consists of different activities aimed at bringing into existence new material objects mostly called 'buildings'. Let us call it 'the building view'.

Of course those who support the building view do not want to forget that sometimes the "new" architectural work is just a pre-existing architectural work that has been adequately transformed. In such circumstances it will be challenging to discuss whether the two distinct architectural works consist in the same material object, and-in case of a positive answer-to explain how it is possible for one physical transformation to make (i) the older work to cease to exist, (ii) the new work to start to

\footnotetext{
*Correspondence: bacchini@uniss.it

Laboratory of Applied Epistemology, DADU, University of Sassari, Asilo Sella, Lungomare Garibaldi 35, 07041 Alghero, SS, Italy
}

exist, and (iii) the material object to continue to exist, without thereby jeopardising the building view. Such explanation will easily involve the idea that architectural works do have different constitutive properties with respect to the material objects they consist in, and which they share their properties with. In a similar way, we may judge that the mere material object the painting painted by artist $A$ consists in can survive the physical transformations - the new incisive brush strokes-by which artist $B$ makes her new painting start to exist, actually by vandalising $A$ 's work of art-or, in any case, by making it cease to exist. One may say that, perhaps, architectural works do have all the properties of the material objects they consist in, but have in addition some properties not possessed by the objects, such as, for example, some aesthetic properties. However, this discussion falls under the much more general issue of grounding the metaphysical difference between a work of art and the mere object it consists in, and is beyond the scope of this paper.

Those who defend the building view will not be so naive as to maintain that architects cannot be in practice as architects also through creating things that are 
neither buildings nor-under some conceptions-material objects. Think of a urban square: this is a kind of thing that typically architects bring into existence, in spite of its apparently lacking some central features that identify material objects. In fact, differently from ordinary material objects, urban squares seem to be entities topologically open in all directions but downward. No doubt they have no upper boundaries. But they also seem open in the four cardinal directions, since their boundaries (typically the façades of the buildings surrounding them) will rather be regarded as parts of the buildings themselves than as theirs. Nor can we consider urban squares as mere surfaces, because-to say one thingthey seem to include the empty space people can walk through. Nonetheless it seems perfectly adequate to see urban squares as spatiotemporal particulars possessing a shape, a size, a location, and even a history. So the building view should be extended as to also account for those architectural works that coincide with spatiotemporal particulars other than material objects, yet much similar to them. I assume such extension to be not particularly problematic.

\section{The many different things the architectural work can be taken to be}

Rather, I want to stress that the building view is just one of many options; and, some alternative conceptions may capture more incisively what architects really do, or are asked to do by our societies, at least on some occasions. A first and fundamental choice is about considering architectural works to be concrete or at least spatiotemporal entities-as the building view does-or, by contrast, abstract entities lacking a spatiotemporal location. Abstract entities, in turn, can be either mind-independent (paradigmatic universals, ${ }^{1}$ as well as abstract particulars if any) or mind-dependent (ideas).

If you consider architectural works to be abstract entities, then-in opposition to advocates of the building view-you do not take them to need to be physically erected in order to fully exist. So you will allow architectural works to also reside in "those things ancillary to built structures, such as architects' drawings and models, blueprints, and computer renditions" (Bicknell 2014); and, perhaps even in complex ideas in the architects' minds, before they are externally represented, expressed or communicated. Similarly, symphonies as musical works, as far as they are regarded as abstract entities, can be said to exist in musical scores before they are

\footnotetext{
${ }^{1}$ Not every philosopher agrees that (all) universals are abstract. See e.g. Armstrong (1989).
}

performed, and perhaps even in the composers' minds before they put pen to paper.

Although not every abstract entity is necessarily a type, a common way of seeing one kind of works (symphonies included) as abstract entities is recognising them as types, that is, as general sort of things admitting of particular concrete (or at least spatiotemporal) instances, or tokens (Wetzel 2008). The same can be done with respect to architectural works. At first glance understanding architectural works as types may appear as an ill-conceived idea, because it may seem that for something to be a genuine type it must admit of several possible concrete instances possessing different spatiotemporal locations; while, on the contrary, architectural works as abstract entities (although lacking themselves, of course, a spatiotemporal location) are often essentially characterised by time- and site-specific properties in the first place, thus limiting the spatiotemporal locations of their tokens to just one. On further inspection, however, this is not a serious difficulty. Indeed for something to be a type it is sufficient that its tokens can differ in some respect, not necessarily in their spatiotemporal location. So there is room for considering architectural works as types also if they appear to be essentially characterised by time- and site-specific properties, provided that two possible genuine realisations of the work are not necessarily identical under every respect. ${ }^{2}$ Architectural works as types are possibly expressed in the architectural design (see e.g. Armstrong 1995). In any case, it is important to keep in mind that what we have to do with here is a trichotomy: abstract entity that is not also a type versus type versus concrete particular. ${ }^{3}$

A second important choice is that among a narrow and a broad view of the architectural work. On a narrow view, the spatial boundaries of the architectural work coincide with (or, come close to) those of an imaginary material object mereologically constituted by all and only those items that were (or should be) materially erected, modified, transported and placed, or merely left unchanged by the construction company as an effect of the architect's instructions (and, also, by the space within); and, the properties the work constitutively possesses are limited to the intrinsic, perceivable physical properties that are grounded on the intrinsic, perceivable physical properties of those items. On a broad view, on the contrary, the spatial boundaries of the architectural work can be

\footnotetext{
${ }^{2}$ Although types do admit of more than one token by definition, some views of the architectural work, or of the work of art, as a type may contingently entail some such types to have just one token.

${ }^{3}$ I will assume for simplicity's sake that all tokens (of some type) are spatiotemporal (if not concrete) particulars, although this can easily be shown to be not a general truth.
} 
much more extended than that, and also, the work can constitutively possess much more kinds of properties. For instance, a supporter of the broad view may argue that whenever a new building designed by an architect is erected, the authentic architectural work that is thus produced is of very greater area or size: a new district or, even, a new town. ${ }^{4}$ In this extreme sense, town $X$ is the only architectural work produced by all of the architects ever working in $X$, and at each instant of time the umpteenth and ephemeral author of $X$ is the architect(s) that most recently architecturally modified $X$ by creating or transforming a proper part of $X$.

Note that the 'imaginary material object' employed in the (rough) definition of the narrow view provided above needs not to coincide with the architectural work itself. In fact not only a narrowly (and, similarly, a broadly) identified work can be an abstract entity, and possibly a type, rather than a concrete particular (the second split being orthogonal to the first), but also-and we come to a third fundamental choice-it can be an event rather than an object. The third option is orthogonal to the other two; hence the building view is just one in twelve possibilities. Indeed, if we interpret (as we should) the narrow/ broad division as a continuum offering infinite choices, we have reasons to consider the building view as even less unavoidable.

\section{The architectural work as an event}

But how should we interpret the idea that the architectural work is really an event? Of course there are plenty of approaches in the history of architecture that have stressed how important it is for architects to think in terms of processes. Yet these suggestions were rarely meant to undermine the building view, which on the contrary was implicitly presupposed. Where can we find an architectural work literally regarded as an event?

To begin with, Lopes (2007) has maintained that while according to standard Western ontology an architectural work is an object token and, more specifically, a material building, in traditional Japanese ontology architectural works are event tokens, which may also include one or more round of reconstruction. ${ }^{5}$ This explains how it is possible that tourists visiting today the goshoden (the main sanctified structure) of the Ise Jingu, one of the most important and most visited Shinto shrines in Japan, do visit the same architectural work "launched" in the

\footnotetext{
${ }^{4}$ One might even maintain that there is one and a single architectural work, 'the One', consisting in the world itself.

5 Indeed Lopes uses the word 'building' as a synonym of 'architectural work', and consequently his claim takes the form that in traditional Japanese ontology buildings are event tokens, while in Western ontology they are concrete object tokens.
}

eighth century CE although the goshoden itself has been rebuilt about every twenty years, each time in one of two adjacent lots, introducing numerous changes in material and spatial specifications from one rebuilding to the next. ${ }^{6}$ Also consider not only that events-differently from objects-are commonly conceived as having temporal parts, that is, parts corresponding to the intervals or moments through which they perdure (Simons 2000), ${ }^{7}$ but also that, while objects are supposed to have relatively crisp spatial boundaries and vague temporal boundaries, events, by contrast, would have relatively vague spatial boundaries and crisp temporal boundaries (Casati and Varzi 2015). Thus acknowledging that in traditional Japanese ontology architectural works are event tokens would account for traditional Japanese vernacular architecture's employing ephemeral building materials (because there is nothing wrong with events ending), and even for Japanese modernism's putting up works for a very brief lifespan (think of Toyo Ito's Nomad Restaurant, 1986).

Is there room for the idea that an architectural work is really an event also in the Western world? A range of recent work by geographers drawing primarily on the insights of actor network theory (Lees 2001; Llewellyn 2003; Jacobs 2006; Jacobs et al. 2007; Latour and Yaneva 2008) and affectual geography (Latham and McCormack 2004; Adey 2008; Kraftl and Adey 2008; Rose et al. 2010) has started to conceptualise particular architectural works less as material objects than as performances or processes, that can be seen in turn as formed or ordered series of events (Quinton 1979: 197). Many of these authors prefer to avoid the term 'building' precisely to reject the presumption that what they are referring to is a material object. This is the main reason why some (Jacobs 2006; Rose et al. 2010) introduced the term 'big things' as a more neutral expression. In consequence, many architects aware of this kind of literature have explicitly embraced the idea that what they essentially and eventually produce as architects are rather complex spatial processes prioritizing social and economic objectives than material objects (Lorne 2016).

\footnotetext{
${ }^{6}$ The same holds for more than thirty other Japanese Shinto shrines that are regularly rebuilt.

${ }^{7}$ According to Simons (2000), we should acknowledge that the main duality is that among continuants-any item which exists in time and which has no temporal part, that is, a part that exist solely because the item's existing at a certain time-and occurrents-items in time that do have temporal parts. Typical continuants are material objects: but note that also astrophysical items like galaxy clusters and social items like committees are continuants. On the other side, occurrents seem to mainly consist in events. According to Simons, four dimensionalists like Sider (2003), who think that ordinary material objects have temporal as well as spatial parts, are saying that ordinary material objects are occurrents, not continuants, which means disruptively denying that "they persist by enduring, existing as one and the same at different times".
} 
As a general principle, also those who categorise architectural works as events need to decide where to lie along the broad/narrow view continuum. A minimal characterisation of the architectural event might consist in the mere being erected, enduring and decaying (or, being destroyed) of the material object(s) normally called the building(s)'. Perhaps this is the most adequate vision of the event that the goshoden of Ise Jingu may consist in. By contrast, a broader understanding of the architectural event would require-for instance-to see it as "various materials being held together in specific assemblages by work of various kinds" (Rose et al. 2010: 334) including social practises, cultural habits, political institutions, the experiencing of the architectural work by human and perhaps even non-human beings, the conceiving of it in certain ways and the attributing to it of certain functions, significance, aesthetic value, the discourses surrounding it, and so on. And, again, one can (or better, must) combine each of these separate options with the idea that the architectural work is the event token or, as an alternative, the event as an abstract entity, somehow identified.

\section{The architectural work as an abstract entity}

As previously clarified, it is possible to understand an architectural work as an abstract entity in two ways: as a mere abstract entity, and as an abstract entity that is also a type. While mere abstract entities do not admit of more than one and a single concrete realisation, types do. Bearing this difference in mind, let us try to identify the abstract entity that the architectural work might be.

A most natural move is perhaps identifying it with the content of the architectural design. But this move will reveal hasty. For the content of the architectural design often contains too little information in respect to the abstract entity the work should consist in, if at all. Architectural works are often constituted also by properties over which the architectural design normally remains silent, such as, environmental, geographical or social properties. In fact, if we imagine to have the capability to relocate buildings to a far way location after meticulous stone-by-stone transfer, still we must admit that some of the corresponding architectural works would not survive the change. For example, Palazzo Sansedoni, or the Notre Dame de Paris cathedral, would not survive a relocation to Tokyo-while an anonymous block of flats probably would (Bacchini 2017). I take the reason to be that some architectural works, but not all, are to be broadly identified. By contrast, taking the architectural work to reside in the content of the architectural design normally is identifying it narrowly. This is the first reason why we should abstain from always equating the abstract entity the architectural work may consist in with the content of the architectural design.
Of course some architectural designs can and actually do make reference to some environmental, geographical or social properties as constitutive properties of the work. Could we take the corresponding broadly identified architectural works to consist in the content of such designs? It seems to me that the answer is, again, 'no'

Consider, first, that in any case identifying the architectural work with the content of the architectural design entails allowing that the work is completed when the design is completed, and before that any physical realisation appears.

Secondly, we can assume each architectural design to admit of multiple realisations-intending as 'multiple realisations' possible concrete particulars that, though possessing all of the constitutive properties prescribed by the architectural design, still differ in some other nonconstitutive properties, such as location, time of construction or materials, but also species of birds nesting on surrounding trees, projected shadows, smell in the air, political opinions of the nearby community, and so on. I think that there is room for ascribing multiple realisability also to those architectural designs indicating some environmental, geographical or social properties as constitutive properties of the work. So, if architectural works have to consist in the content of architectural designs, then architectural works are types in any case.

Now, consider the architectural design of Under Pohutukawa Residence by Herbst Architects (Fig. 1). Suppose that it does appoint some environmental and geographical properties; and suppose we take the work to consist in its content. When the work is concretely instantiated for the first and perhaps only time in Piha North, New Zealand, in 2011, this instantiation inevitably ends in exemplifying much more properties than those specified by the architectural design (each concrete particular exemplifying an infinite number of properties). Most of them will likely be unpredictable. Shall we subscribe-as we should - to the point of view that none of them is constitutive of the work? I think we will not. For-as the 2012 NZIA New Zealand Architecture Award Jury expressed themselves - "the house is a beguiling essay in the relationship between structure and setting, order and nature". Who can say that a certain view from the window, interaction of shadows, smell of wood or attitude of the nearby community towards the house can be dismissed as contingent? On the contrary, one would say that no property of the house or its context can be dismissed as contingent. Accordingly, the work cannot be identified with any type expressed by the architectural design. It rather is either the broadly identified concrete particular, or a broadly identified abstract entity that is not also a type. In the latter case, however, it seems necessary for the mere abstract entity to be only 


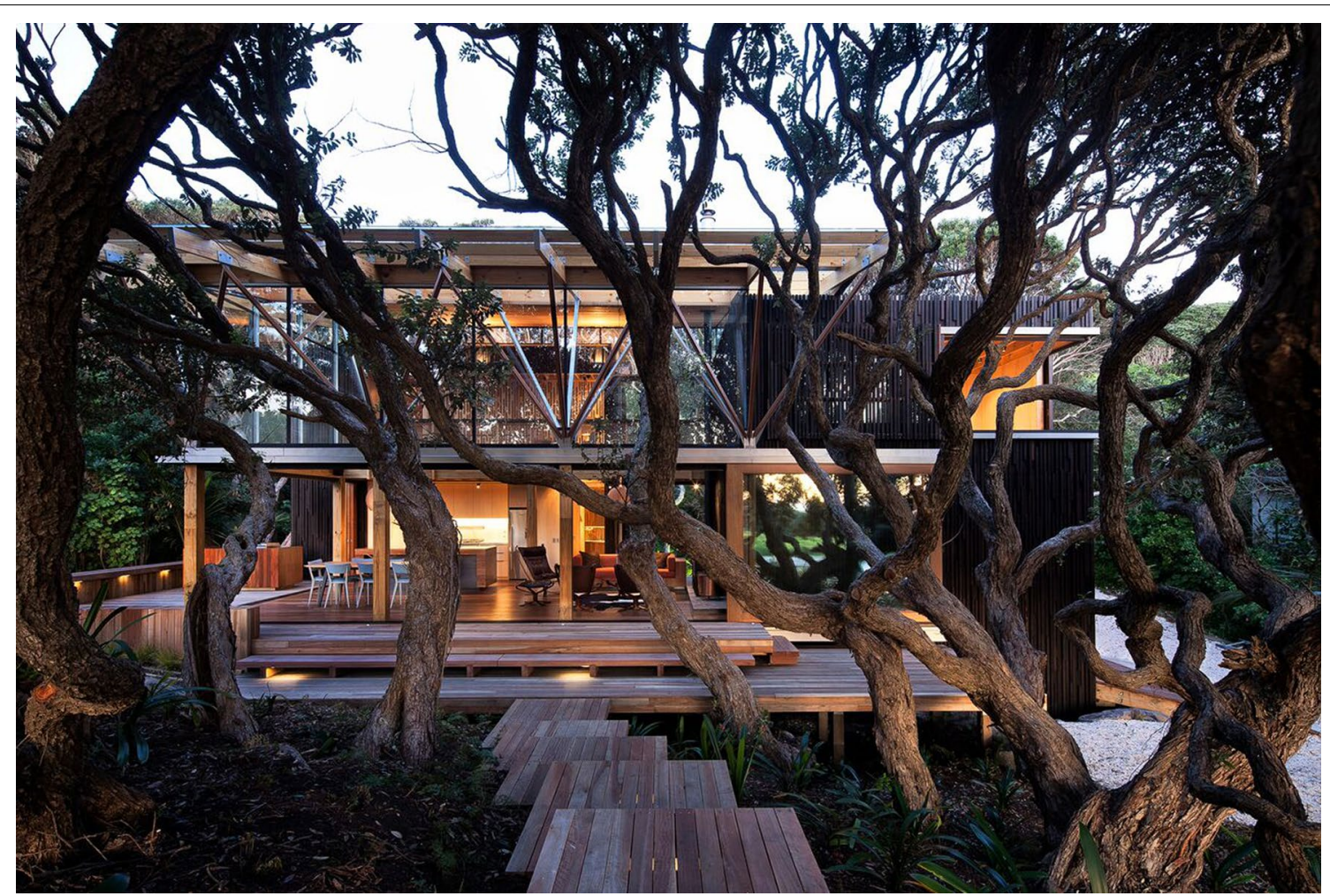

Fig. 1 Herbst Architects, Under Pohutukawa Residence (2011), Piha North, New Zealand. Photographer: Patrick Reynolds. Contractor: John Armstrong

determinable after that the concrete particular appears, not before, because the architectural work is not actually completed before it is physically realised. Thus, either such abstract entity will include all of the properties of the realisation as constitutive, or will it include as constitutive just some: all of the properties specified as constitutive by the architectural design, of course, and in addition many properties unpredictable after the design. Possibly for a property to be constitutive is a matter of testing our intuitions against imaginary scenarios and reaching intersubjective compromises. In this regard, the nature of the work as an abstract entity is a matter of argumentation and negotiation.

So, architecture is not a two-stage activity after all-at least not always. ${ }^{8}$ I would say that modular architecture, producing modular buildings such as kit houses popular in North America in the first half of the 20th century, or

\footnotetext{
${ }^{8}$ Goodman (1968) baptised 'two-stage arts' those arts in which there is a distinction between the completion of a work of art and its occurrence as an item for aesthetic perception. Classical music, for instance, is a two-stage art, while jazz is rather a one-stage art, at least if we consider improvisation as one of its key aspects. We need not to commit to the thesis that architecture is art (either always or only in some specific circumstances) in order to test the hypothesis that architecture is a two-stage activity.
}

Tom Sandonato and Martin Wehmann's kitHAUS pre-fab modules nowadays, is paradigmatically two-stage; and, also stereotypical and vernacular architecture is twostage, as far as we find no difficulty in regarding the corresponding architectural works as types expressed by the architectural design (hence normally narrow). ${ }^{9}$ But the more we have to do with originality and inventiveness, the less architecture appears two-stage. Ironically, then, the more architects are imaginative and resourceful, the less they are to be considered as the unique authors of the architectural works they design.

\section{The closeness between architecture and cooking}

Few other fields of human activity resemble architecture in this respect. One (possibly the only) is cooking. In the first place, like for architecture and unlike for many other arts and fields, it is prima facie open to question how to identify the 'culinary work' with regard to the object/ event dichotomy, the mere abstract/type/token trichotomy and the broad/narrow continuum. Secondly, like for architecture, considering cooking as a two-stage activity, and recognising the culinary work as a type identical to

\footnotetext{
${ }^{9}$ See Davies (1994) for a somewhat different view.
} 
the content of a recipe (hence normally narrow), are easy options if we have in mind traditional or conventional cooking, but are problematic when we take into account more experimental and creative approaches.

Take oeuf à la coque, Linzer torte or tagliatelle al ragù: it is natural to hold that, in these cases, the culinary work is the narrow type expressed by the recipe, while my and your executing the recipe produce two occurrences of the culinary work, and in doing so, perform the second of the two stages cooking consists in. Of course, we remain also free to say that the culinary works are the concrete particulars, or the mere abstract entities corresponding to each of them. But this option-like for architecturebecomes more and more attractive, even inescapable, as we examine forms of cooking progressively more tending to innovate and characterised by a higher degree of freshness and novelty.

One of the reasons why architecture is more similar to cooking than to classical music or etching, is that the architectural design is more similar to a recipe than to a written score or a plate. While the written score and the plate always fix all of the constitutive properties of the work (the former by using a notational language, and the latter by stipulating that the only way to assure that a print possesses all of the constitutive properties of the work is verifying that it was taken from that plate), the architectural design and the recipe increasingly fail to do so as originality prevails over conventionality. ${ }^{10}$ You can be certain to be eating genuine Linzer torte even if you have made it at home, provided that you have followed the recipe closely. ${ }^{11}$ On the contrary, you may legitimately doubt to taste genuine Dripping of Fish (2004) if it has not been prepared by Gualtiero Marchesi or his staff, independently of how strictly you have complied with his own instructions (Fig. 2). Indeed Dripping of Fish is a dish inspired by Jackson Pollock's Number 8 (1949)—and you obviously do not believe that you can create a genuine occurrence of Pollock's Number 8 simply by distributing

\footnotetext{
${ }^{10}$ Similarly, Nannicelli (2011: 408) holds that "musical scores and theatrical scripts are work-determinative, but architectural plans are not" and "architectural works differ from musical and theatrical works insofar as their existence and their identities depend upon their instantiation (i.e. with what materials, in what geographical location, in what sociohistorical context they are built)". One difference between Nannicelli's position and mine is that I take architectural plans to fail to be work-determinative not always, but only in some occasions. A second difference is that I think that, even when architectural plans do fail to be work-determinative, it is not necessary to adopt the building view-because the architectural work might also be understood as a mere abstract entity that nonetheless is only determinable after that the one corresponding concrete particular has appeared.

${ }^{11}$ However, we must admit that recipes do evolve, often as an effect of the dishes prepared after them. The evolution of recipes, in turn, has important consequences on the issue of their authenticity. See Borghini (2015).
}

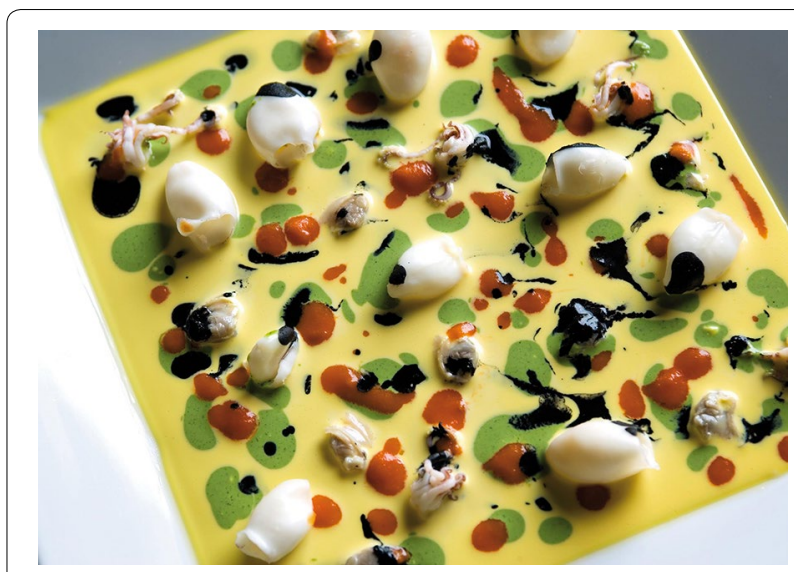

Fig. 2 Gualtiero Marchesi, Dripping of Fish (2004). Photographer: Massimo Borghi

oil, enamel, and aluminium paint on a canvas following Pollock's own instructions.

However, one may object that my argument is ill-conceived. I am suggesting that there is a similarity between three works-Marchesi's Dripping of Fish, Jackson Pollock's Number 8, and Herbst Architects' Under Pohutukawa Residence-in that the three of them are not completed before being physically realised, and therefore cannot consist in the sets of instructions produced at the end of the alleged first stage of the art they pertain.

But while this appears to be true of Number 8 and Under Pohutukawa Residence, both of which consist in one and a single, non-reproducible concrete particular (or, at most and perhaps not in the Number 8 case, in a mere abstract entity only determinable after that the one corresponding concrete particular appears), Dripping of Fish may rather seem a type. After all, Marchesi seems to have physically realised it plenty of times. So isn't cooking two-stage also in the Dripping of Fish case? Wasn't Dripping of Fish, as a work, completed before Marchesi realised it for the thousandth time?

The problem, I think, is that we forget that cooking is special in that each concrete particular is necessarily destroyed ${ }^{12}$ by the one person that has a full experience of it. This is why Marchesi had to replicate Dripping of Fish plenty of times: because the original Dripping of Fish was actually destroyed in 2004 when someone (perhaps Marchesi himself) ate it ${ }^{13}$; and, replicating it again and again was the best way to let other persons have an experience as closest as possible to his. Strictly speaking,

\footnotetext{
12 Or brought to an end, if it is an event.

${ }^{13}$ Of course, if Dripping of Fish as a culinary work is to be an event, we cannot in the strict sense eat it-although we can enjoy it by eating the food that it employs for occurring.
} 
then, there is no culinary work named 'Dripping of Fish' and consisting in a type pre-existing to its instances. Rather, there are plenty of works-Dripping-of-Fish ${ }_{1}$, Dripping-of-Fish, Dripping-of-Fish 3 , Dripping-of-Fish ${ }_{4}$, and so on-each consisting in a concrete particular very soon destroyed by someone (or, perhaps, gone rotten), and sharing as many properties as possible, though necessarily not all of them. ${ }^{14}$ Since no property possessed by any of them can be dismissed as contingent for that work, none is the same work as any other in the list. 'Dripping of Fish' is just the name of a collection or a kind (a type, if you prefer) of culinary works that is not a culinary work itself.

The situation would be identical for architecture, and painting, if also in these fields concrete particulars were necessarily destroyed by people fully perceiving them. Suppose that this were the case, and Pollock and Herbst Architects had to continuously replicate Number 8 and Under Pohutukawa Residence in order to let people have an experience similar to that of their destroyers. We would have two expressions-'Number 8' and 'Under Pohutukawa Residence'-to refer to each of the two families of very similar works produced in series. But, again, there would be no work consisting in a type named 'Number 8' or 'Under Pohutukawa Residence'-rather, there would only be works as concrete particulars (or, at most and perhaps not in the Number 8 case, as mere abstract entities only determinable after that the one corresponding concrete particular has appeared) sharing some but not all the properties not dismissible as contingent for any of them.

By contrast, if culinary works were not doomed to early destruction and could be gustatively experienced by infinitely many people without being dissolved, Marchesi would likely have produced just Dripping-of-Fish - $_{1}$ or at most a few more variations, as painters do-and then would have moved on. Indeed painters do happen to paint sequences of works that are almost identical to each other. Cézanne painted more than twenty Views of Mont Saint-Victoire from 1885 up to 1906, and five The Card Players between 1890 and 1895; Van Gogh depicted thirteen Head of a Peasant Woman with White Cap (18841885), seven Vase with Sunflowers (1888-1889), five Portrait of the Postman Joseph Roulin (1888), seven Mulin de la Galette (1886-1887) and thirty-six Self-Portrait; and while Monet's Water-Lilies (1897-1926) are more

\footnotetext{
${ }^{14}$ Note that it is not necessary for every realised Dripping of Fish ${ }_{i}$ to have been an imitation of the original Dripping of Fish ${ }_{1}$. I speculate that many members of the chain are replicas of some previous individual member numerically different from Dripping of Fish ${ }_{1}$. Therefore it is possible that evolution occurred along the series, and that the properties shared by all its members are fewer than we are inclined to presume.
}

than one hundred, Cézanne's Still Life (mostly very close to each other) are nearly two hundreds. Yet the works are invariably the concrete particulars. Nobody would say that there is a work of art, whose name is Portrait of the Postman Joseph Roulin and whose author is Vincent Van Gogh, consisting in one type and instanced five times. The same goes for Marchesi's Dripping of Fish.

\section{The architectural and the culinary work as broadly identified}

Therefore stereotypical and vernacular architecture stands to Under Pohutukawa Residence as stereotypical and traditional cooking stands to Dripping of Fish ${ }_{i}$ (that is, to each single member of the Dripping of Fish series). While in stereotypical cases the work can be regarded as a narrow type specified by the architectural design, or the recipe, when we come to more original and creative cases the work is a concrete particular, or at most a mere abstract entity only determinable after that the one corresponding concrete particular appears. Moreover, such concrete particular (or, such mere abstract entity) is often to be identified broadly.

Understanding why this requirement holds for architecture-and in the first place what it is for an architectural work to be identified broadly-is relatively simple. We judge that we can relocate an anonymous block of flats, or a kitHAUS pre-fab module, without attempting on its identity. Therefore, no environmental or geographical property is constitutive of the architectural works that the anonymous block of flats, and the kitHAUS prefab module, are (or, are instances of). Therefore, such architectural works can be identified narrowly; and we are free to equate them with the concrete particulars, a mere abstract entity, or the type expressed by the architectural design, which is normally narrow.

In the Under Pohutukawa Residence, however, we cannot dismiss as contingent any of relational properties between the house and its amazing natural context. Not only destroying the beach, or the Pohutukawa trees, would destroy the work (or, this instance of the work). Also eliminating the view from a particular window, or the way the projected shadows intersect in the afternoon, may be lethal to it. Thus the work must be identified broadly, so as to include all those relational properties. The architectural work is much more extended than the house, both in a spatial and in a metaphysical sense.

Note that including in the architectural work part of the environment surrounding the building, and the relational properties whose relata are the construction, on the one side, and some entities belonging to an even larger geographical context, on the other side, is not the only possible way of conceiving an architectural work as broadly identified. For example, you can think of some architects 
as essentially and eventually producing things (whether they be concrete or abstract) much more complex, enlivened and multiple than mere material buildings (Lorne 2016), animated by many human and non-human actors (Jacobs and Merriman 2011), embedding "the practical and effective or 'non-representational' import of architecture" (Lees 2001: 51), and purposely addressing social, economic and political issues.

But what does it mean for a culinary work to be broadly identified? And, why do we need to identify broadly Dripping of Fish ${ }_{i}$ ? We have previously said that being prepared by Marchesi, or at most by a member of his staff, is fundamental for it to be authentic. This is what normally happens in painting, where we posit that the artist must have worked at first hand on her materials in fashioning her artwork. ${ }^{15}$ Yet a painting is normally identified narrowly. Why, and how, should the set of properties that cannot be dismissed as contingent for Dripping of Fish include properties instantiated beyond the borders of the dish?

The point is that Marchesi himself theorised that the culinary work is a composite item made of several different parts he used to take care of personally: the dish, of course, but also the cutlery, the glasses, the tablecloth, the plates, the pots, the waiting service, the restaurant as an architectural space, the kitchen. He thought of cooking as a "total experience", and he explicitly and purposely aimed to create a compound emotion in his guests by controlling each of those several factors. And he is notoriously not alone among first class chefs to do so: think, for example, of Paul Pairet's single-table restaurant Ultraviolet (Shanghai, 2012) serving culinary works among whose essential ingredients are lights, projections, sounds, music, scents, air flow, temperature (Figs. 3, 4). Therefore Dripping of Fish ${ }_{i}$ must be identified broadly. ${ }^{16}$ Again, it is impossible to tell the constitutive from the

\footnotetext{
15 We seem to be a little more concessive with cooks than with painters in allowing that a member of their staff (though no one else) can directly work on the materials and fashion the work under their supervision or by their appointment. Yet sometimes we are indulgent with regard to painters, too. We cannot imagine that Michelangelo painted the vault of the Sistine Chapel without the help of some assistants. And-to extend our attention to visual artists in general-our doubting that each and every of Andy Warhol's works produced through Factory Additions, the print-publishing business established by him, was directly made by Warhol, does not end in any drastic revision of his catalogue raisonné. On the other hand, many newspapers commented on Marchesi's death, in December 2017, saying that his dishes disappeared with him.

16 It would be wrong to take the empirical author's explicit instructions as a necessary condition for the culinary or architectural work to require a broad identification. Rather, it seems to me fundamental that-to employ a terminology taken from Eco's theory of interpretive cooperation (1979, 1990) - the Model Author of the work, whether the latter be initially identified narrowly or not, does demand (as an interpretive norm) that the work is not identified narrowly.
}

accidental properties. Like for Under Pohutukawa Residence, you cannot dismiss any of the contextual properties as contingent. The conclusion is that, for Dripping of Fish $_{i}$ to be authentic, it must be in a place sanctioned by Marchesi as 'the right place': typically, in the restaurant $\mathrm{Il}$ Marchesino. I think that we all agree with this conclusion in judging that, if also another restaurant served the very same dishes as Il Marchesino (maybe by shoplifting the ready dishes directly from its kitchen), yet it would not be able to serve any genuine Dripping of Fish ${ }_{i}$.

Note that it would be a mistake to equate the broadly understood culinary work with the "total experience", and even considering such experience as a necessary condition for the culinary work to exist. For, these equivalences would entail that, if one day Marchesi only prepares Dripping of Fish 688 in his closed restaurant, brings it out to an empty table, and no one eats it, there is no culinary work in his restaurant that day. The broadly conceived work is rather a composite machine designed to produce a certain "total experience" in a subject longing to try it. Of course, if the work is a broadly conceived event, then it is a multi-faceted event consisting in the temporary appearing of that machine, and perhaps, also in the arranging for it to appear. The same goes for architecture.

As usual, the problem of fixing sharp temporal boundaries emerges as needing more immediate attention in respect of events than objects. So we can compellingly wonder when the culinary work as an event begins (by the time the dish is served? by the time the preparation starts? by the time the ingredients are produced at different locations?) and, also, when it ends. Is the culinary work, as an event, still going on while the dish is being eaten, and most of the food is either in the eater's mouth or in her stomach? And if no one eats the dish, is every temporal part of the marcescence process also a temporal part of the culinary work as an event? The same stimulating questions, mutatis mutandis, can be raised about the temporal boundaries of the architectural work as an event: are the designing process or the previous states of the place-and on the other hand the construction's falling in disrepair, its being a ruin or even its being nonexistent by now (Judkins 2014) - temporal parts of the architectural work as an event?

By definition the aesthetic perception of a work cannot be part of the work itself. So (supposing the culinary work to be an event) neither the tasting nor the "total" experience of the person who eats, as far as they coincide with the aesthetic perception of the work, can be part of it. But we must acknowledge that a chef may stipulate that, just as the food is one among many objects used by the event for occurring, in the same way the tasting experience of the food by the eater is just part of the event the culinary work consists in, and does not coincide with 


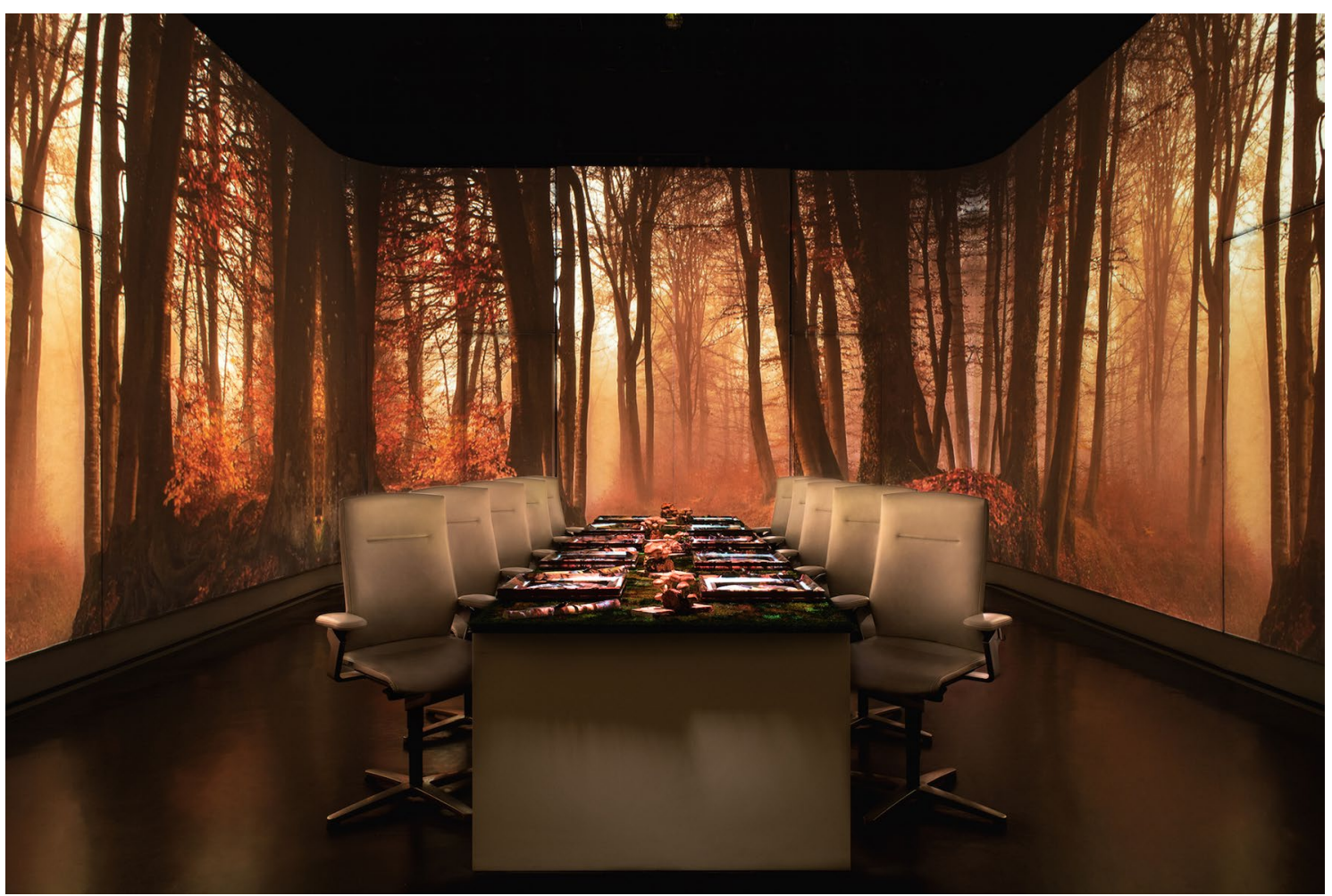

Fig. 3 Paul Pairet, Ultraviolet (2012), Shanghai. One flavour of the dining room of the restaurant. Photographer: Scott Wright, Limelight Studio

the aesthetic perception of it. Such a stipulation seems to allow for the tasting experience of the food, and even for some broader version of it that we can call the "total experience of the food", to be included in the culinary work, that in consequence may go on also while the person is eating, or has eaten the food. (One may wonder: in this case, can digestion and defecation be two temporal parts of the culinary work, too? How long can the culinary work go on at best?)

Definitely experiences can be part of both a culinary and an architectural work, provided that they are not the ultimate aesthetic experiencing of the work itself. So Marchesi could have established that for a genuine Dripping of Fish ${ }_{i}$ to be there the occurring in the eater's mind of a visual experience of the snow from the window, or the stirring up of painful memories in the people dining in the nearest table, are needed. And, an architect could fix as constitutive of the work whatever emotive reactions of human and non-human actors to the material building and to the events happening in it (see Rose et al. 2010), or the occurring of some specific kind of emotions on some specific occasions. True, this is not what architects normally do. Yet they do something close to this when, for instance, they bind the processes they design to specific, highly ephemeral communities, maybe engaged as active participants, thus implicitly making the dispersing of those communities also the end of the architectural works.

An interesting point in that regard is whether the powers of the sanction of the architect, the chef and the artist are absolute and, in any case, alike. Has a cook the power to make her culinary work constitutively $X$-specific? Certainly one can make a culinary work de facto site- or time-specific by requiring some perishable location-specific (geographical indications), ${ }^{17}$ or seasonal, food products as essential ingredients for its preparation; but my question is rather whether Marchesi had the power to arbitrarily decree that Dripping of Fish ${ }_{i}$ can only exist in Milan (hence, not merely in Il Marchesino) or, maybe, in a stormy night, in winter time, or during the Pontificate of Joseph Ratzinger (2005-2013). The same questions can be raised for architecture. Has the architect the unquestionable power to establish that her work can only exist for a three-year lifespan, or if the building is plant-covered or inhabited by a certain kind of people?

If one subscribes to a constructivist view of culinary works, according to which they "are the outcome of a

\footnotetext{
${ }^{17}$ In this regard see Borghini (2015: 728; 735).
} 


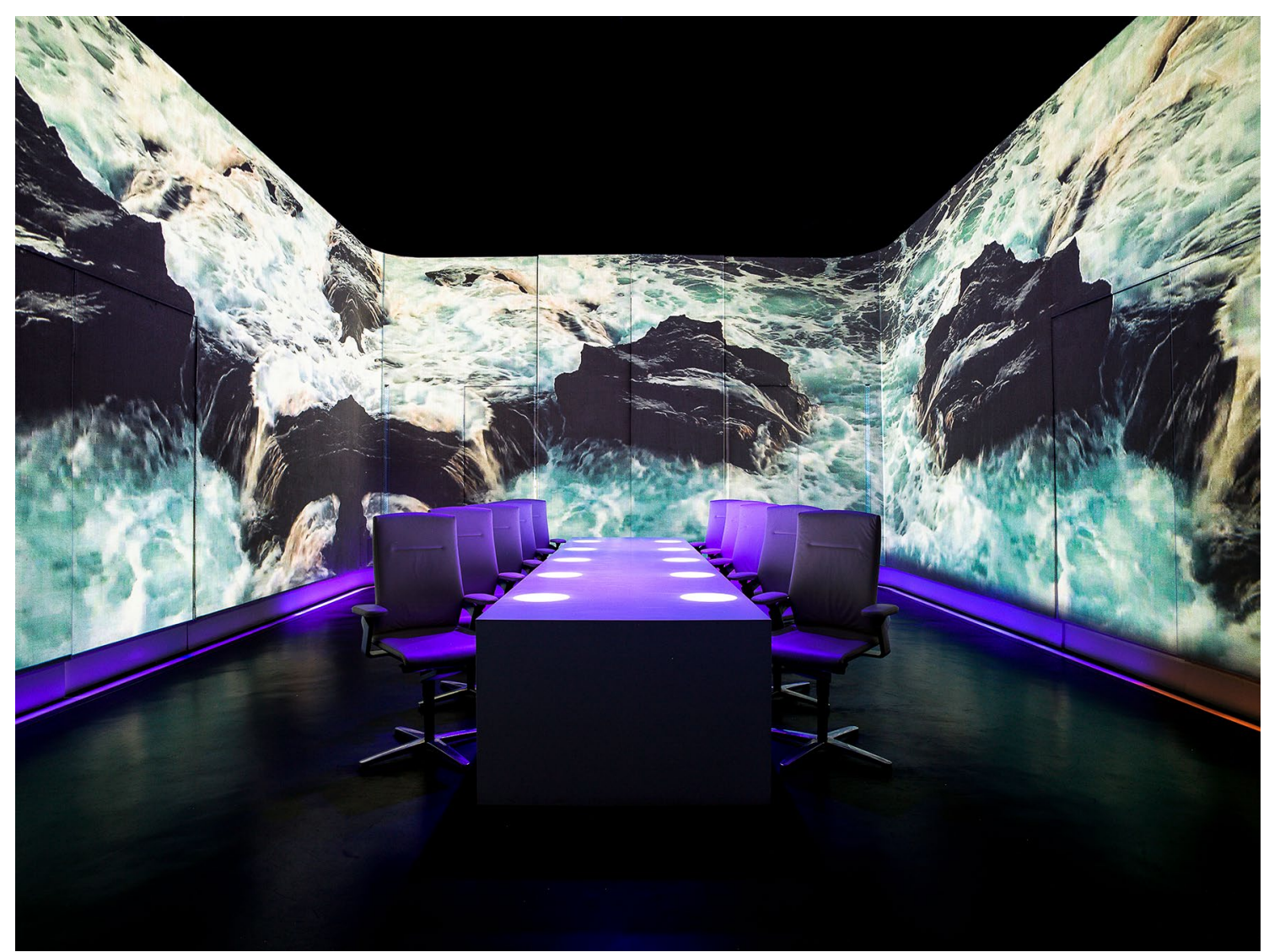

Fig. 4 Paul Pairet, Ultraviolet (2012), Shanghai. Another flavour of the dining room of the restaurant. Photographer: Scott Wright, Limelight Studio

selection process ultimately guided by human fiat" and "typically performed by a speech act" (Borghini 2015: $724 ; 727)$, doubts about allowing the cook an absolute power over the work she creates (whether it be a type or a token) seem to dissipate. Similarly, Irvin (2005: 321) has maintained that the artist's sanction has supreme authority for fixing the constitutive properties of the work of art, because "the actions and communications that serve to establish a sanction are, generally speaking, expressions of the artist's intention [...] just as painted marks or other physical manipulations within a medium". On the other hand, we may suspect that we would not follow an architect or a cook demanding too extravagant conditions (however motivated) for considering the work they designed as genuinely spatiotemporally existing ("the visitor-or, the eater-must be dating for the first time as a single parent")-just as we would perhaps not follow van Gogh also "if he had publicly declared in 1890 at relevant points during the production of Wheatfield Under Thunderclouds that it was to be conceived as an unconventional work of art among whose essential features had to be included new physical features at different moments in the future-that is, all the new physical features caused by a series of hard hammer blows to be delivered by the curators to the work in 1990, 2090, 2190 and so on" (Bacchini 2017: 90).

A challenging case is represented by an architect demanding that, say, for her Miraculous Church to genuinely exist, it is necessary that most if not all the people visiting the cathedral truly believe that it really is a miraculous church. Similarly, a cook-or even a local community - might establish that, say, for the Risotto alla Milanese type to be genuinely instantiated, it is necessary that the person who is going to eat the dish truly believes to be in Milan, no matter that she is elsewhere; hence if you happen to eat the dish in Turin, but you believe to be in Milan, what you are experiencing is an authentic token of the culinary work Risotto alla Milanese, and by contrast, if you happen to eat the dish in Milan, but you believe to be in Turin, what you are experiencing is something else.

\section{Conclusions}

I have shown that, when we have to decide what the architectural work ultimately consists in, we must take position with respect to a number of options, such as 
the object/event division, the mere abstract entity/type/ concrete particular division, and the broad/narrow continuum (along which there are infinite possibilities to select), which in the first instance are freely combinable. The first notable consequence is that what I have called 'the building view', that actually unites the object view, the concrete particular view and the narrow view, is no longer an obvious choice.

Moreover, I have argued that some combinations do appear problematic in specific circumstances. For example, adopting the type view in conjunction with the narrow view is simpler when we examine stereotypical or vernacular architecture; by contrast, if we have to do with more experimental and creative approaches, it seems more appropriate to identify the architectural work with a broadly identified concrete particular or, at most, with a broadly identified abstract entity that can hardly coincide with the content of the architectural design. The same conclusions can be drawn with respect to cooking (the equivalent of the architectural design being the recipe). It was therefore compelling to ask if there are limits to the nature of properties that can be deemed as essential to the identity of a work, and also, whether the powers of the architect's (or, the cook's) sanction in this regard are absolute or not.

It is worth noting in conclusion that an important difference exists between cooking and architecture, which may seem lethal to their very capability of being compared, hence to the heuristic force attributed in this paper to the comparison. The difference is that while the architectural design always pre-exists the realisation of the concrete particulars, and does so also in the case of architectural haute cuisine, this is not necessarily true of recipes, that often just codify ex post all or just part of the constitutive properties of a work physically realised beforehand. Unlike architects, cooks need no recipe in order for their works to concretely occur. However, this difference can be shown to be of less importance and grounded on a contingent fact. Erecting one building is much more expensive (say, roughly, among $10^{5}$ and $10^{8}$ times more) than preparing one dish. Whatever is one's general conception of the nature of the architectural and the culinary work, and whatever properties are regarded as constitutive of this specific architectural work and of that specific culinary work, the ratio between the two costs cannot be subverted. Therefore precautions rationally taken before proceeding to realise a concrete particular are much different in the two fields. Cooks can learn to cook through preparing thousands disastrous dishes, while architects must be trained so as to perform perfectly on the first shot. And clearly, while even the Michelin-starred first class chefs can happen to make lots of varied attempts turning out too viscous or glassy before completing a new culinary work, architects must feel very secure before giving the green light to the construction company. The difference, then, is merely accidental, and rather capable of strengthening the thesis that a basic likeness among architecture and cooking exists.

If costs were as high, and time-scales as long, for cooking as for constructing, upgrading and retrofitting in architecture, cooks would be much more cautious before "seeing what we turn up"; and the role of the recipe would be exactly that of the architectural design in the actual world. Conversely, if erecting and restoring were as cheap and quick as cooking, the function of the architectural design would match that of a recipe; people would definitely realise (instances of) new architectural works without abiding by architectural designs, ${ }^{18}$ and even without the help of architects, who would be educated and trained on a trials-and-errors basis, like cooks.

So we should acknowledge the highest heuristic role to the architectural design as it is used in the actual world. It literally serves in place of the multiplicity of concrete trial and error paths towards the completion of the architectural work that architect would undergo if they only could afford it. Like such very large number of forwarding paths using trial and error, it essentially involves learning, discovering, understanding, attempting, supposing, abandoning, exploring, experimenting, imagining, adding and subtracting, imitating, comparing, testing, giving up, evaluating, losing one's bearing, getting back on course-its main function being not only bringing to the completion of the work, but also allowing architects to make enlightening and inexpensive mistakes along the way.

\section{Authors' contributions \\ This paper has one and a single author. The author read and approved the final manuscript.}

\section{Acknowledgements \\ Not applicable. \\ Competing interests \\ Availability of data and materials \\ Not applicable. \\ Funding \\ Not applicable.}

The author declares no competing interests.

\section{Publisher's Note}

Springer Nature remains neutral with regard to jurisdictional claims in published maps and institutional affiliations.

${ }^{18}$ Thus making architecture, in such occasions, distinctly one-stage. 
Received: 7 September 2018 Accepted: 19 November 2018

Published online: 24 November 2018

\section{References}

Adey P (2008) Architectural geographies of the airport balcony: mobility, sensation and the theatre of flight. Geografiska Annaler Ser B Hum Geogr 90(1):29-47

Armstrong DM (1989) Universals: an opinionated introduction. Westview Press, Boulder

Armstrong AMC (1995) The identity of a work of architecture. Br J Archit 35(2):165-167

Bacchini F (2017) The persistence of buildings and the context problem. In: August K, Schrijver L (eds) Analytic philosophy and architecture. Approaching things from the other side. Japsam Books-Delft University of Technology, Delft. Special issue of Footprint-Delft Architecture Theory Journal

Bicknell J (2014) Architectural ghosts. J Aesthet Art Crit 72(4):435-441 Borghini A (2015) What is a recipe? J Agric Environ Ethics 28(4):719-738

Casati R, Varzi A (2015) Events. In: Zalta EN (ed) The Stanford encyclopedia of philosophy. https://plato.stanford.edu/archives/win2015/entries/events/. Accessed 10 July 2018

Davies S (1994) Is architecture art? In: Mitias M (ed) Philosophy and architecture. Rodopi, Amsterdam

Eco U (1979) Lector in fabula. Bompiani, Milano

Eco U (1990) The limits of interpretation. University of Indiana Press, Bloomington

Goodman N (1968) Languages of art. Bobbs-Merrill, Indianapolis

Irvin S (2005) The artist's sanction in contemporary art. J Aesthet Art Crit 63(4):315-326
Jacobs JM (2006) A geography of big things. Cult Geogr 13(1):1-27

Jacobs JM, Merriman P (2011) Practising architectures. Soc Cult Geogr 12:211-222

Jacobs JM, Cairn S, Strebel I (2007) "A tall storey... but, a fact just the same": the red road high-rise as a black box. Urban Stud 44(3):609-629

Judkins J (2014) On things that are not there anymore. J Aesthet Art Crit 72(4):441-445

Kraftl P, Adey P (2008) Architecture/affect/inhabitation: geographies of beingin buildings. Ann Assoc Am Geogr 98(1):213-231

Latham A, McCormack DP (2004) Moving cities: rethinking the materialities of urban geographies. Prog Hum Geogr 28(6):701-724

Latour B, Yaneva A (2008) Give me a gun and I will make all buildings move: an ANT's view of architecture. In: Geiser R (ed) Explorations in architecture: teaching, design, research. Birkhauser, Basel

Lees $L$ (2001) Towards a critical geography of architecture: the case of an Ersatz Colosseum. Ecumene 8(1):51-86

Llewellyn M (2003) Polyvocalism and the public: 'doing' a critical historical geography of architecture. Area 35(3):264-270

Lopes DM (2007) Shikinen Sengu and the ontology of architecture in Japan. J Aesthet Art Crit 65(1):77-84

Lorne C (2016) Spatial agency and practising architecture beyond buildings. Soc Cult Geogr 18(2):268-287

Nannicelli T (2011) Instructions and artworks: musical scores, theatrical scripts, architectural plans, and screenplays. Br J Aesthet 51(4):399-414

Quinton A (1979) Objects and events. Mind 88(350):197-214

Rose G, Degen M, Basdas B (2010) More on 'big things': buildings events and feelings. Trans Inst Br Geogr 35(3):334-349

Sider T (2003) Four dimensionalism. Oxford University Press, Oxford

Simons PM (2000) Continuants and occurrents. In: Proceedings of the Aristotelian Society, Suppl. vol. 74, pp 59-75

Wetzel L (2008) Types and tokens: an essay on universals. MIT Press, Cambridge

\section{Submit your manuscript to a SpringerOpen ${ }^{\circ}$ journal and benefit from:}

- Convenient online submission

- Rigorous peer review

- Open access: articles freely available online

- High visibility within the field

- Retaining the copyright to your article

Submit your next manuscript at springeropen.com 